\title{
CORRESPONDENCE
}

\section{Treatment of Suspected Pulmonary Embolism in a Super-Obese Individual}

Published information about anticoagulation in patients with obesity presenting with deep vein thrombosis or pulmonary embolism is limited..$^{1-3}$ In addition, clinical trials for the treatment of deep vein thrombosis or pulmonary embolism in obese individuals are scarce, with most trials limiting entry to persons weighing no more than $120 \mathrm{~kg}^{4}$

The case reported here involved use of unfractionated heparin (UFH) followed by warfarin in a super-obese individual presenting with presumed pulmonary embolism.* The World Health Organization $^{5}$ defines class III obesity (also known as "morbid obesity") as body mass index (BMI) greater than $40 \mathrm{~kg} / \mathrm{m}^{2}$. The surgical literature furthers defines BMI of $50 \mathrm{~kg} / \mathrm{m}^{2}$ or above as "super-obesity" ${ }^{3,6,7}$ The patient in this case met the definition of super-obesity (see details below).

A 38-year-old white man presented to the emergency department of a regional hospital with progressive shortness of breath that had been slowly worsening over the previous few weeks. On the evening of presentation, the patient's shortness of breath had reached the point that his family felt it required medical attention. The patient had a history of obesity, and his weight at the time of presentation was $417.3 \mathrm{~kg}$ (918 lb) and height $180 \mathrm{~cm}$ (71 in) (ideal body weight $75.3 \mathrm{~kg}$ [166 lb], BMI about $\left.129 \mathrm{~kg} / \mathrm{m}^{2}\right)$. Oxygen saturation was $74 \%$ (normal range $95 \%$ to $99 \%$ ) on initial examination (room air) but improved to $94 \%$ with supplemental oxygen $(4.5 \mathrm{~L} / \mathrm{min})$. Blood pressure was recorded as $160 / 80 \mathrm{~mm} \mathrm{Hg}$; however, the cuff may not have been of an adequate size for reliable measurement. Heart rate was $94 / \mathrm{min}$ and respiratory rate $24 / \mathrm{min}$. Serum creatinine was $106 \mu \mathrm{mol} / \mathrm{L}$ (normal range $62-124 \mu \mathrm{mol} / \mathrm{L}$ ). Complete blood count showed a white blood cell count of $12.4 \times 10^{9} / \mathrm{L}$ (normal range 4 to $10 \times 10^{9} / \mathrm{L}$ ) with $83 \%$ neutrophils, hemoglobin $125 \mathrm{~g} / \mathrm{L}$ (normal range $115-150 \mathrm{~g} / \mathrm{L}$ ), and platelets $229 \times 10^{9} / \mathrm{L}$ (normal range 150 to $450 \times 10^{9} / \mathrm{L}$ ). International normalized ratio (INR) was 1.2 (normal range $0.8-1.3$ ). Lactate was $0.9 \mathrm{mmol} / \mathrm{L}$ (normal range $0.3-0.8 \mathrm{mmol} / \mathrm{L}$ ). Measured oral temperature was $36.9^{\circ} \mathrm{C}$. Heart sounds were regular, and no added sounds were appreciated. The results of electrocardiography were normal.

*The patient provided informed consent for publication of this report.
The patient was a nonsmoker with no history of lung disease. Medications in the community included furosemide and metolazone, both prescribed within the previous 7 months for treatment of generalized edema. According to the patient, mobility had not been an issue until 1 month before, when he fell and injured his leg. Since then, mobility had been limited, with shortness of breath on exertion.

Given the risk of pulmonary embolism and the difficulty of ruling out this diagnosis because of body habitus, it was decided to treat the patient empirically for pulmonary embolism. With limited information on anticoagulation in a patient with this degree of obesity, and given non-availability of the anti-factor Xa assay at the study institution, it was decided to use UFH.

Available information on anticoagulation involving obese individuals suggested that for initial dosing, a weight-based nomogram, as would typically be used at this hospital (18 units $/ \mathrm{kg}$ per hour), would likely cause a hemorrhagic event..$^{2,3}$ Using information presented by Myzienski and others ${ }^{3}$ in their review of UFH in morbidly obese patients, it was decided to start UFH at 2000 units/h (4.8 units/kg per hour based on absolute body weight) with no bolus dose. Baseline partial thromboplastin time (PTT), measured just before initiation of UFH, was $27.7 \mathrm{~s}$ (hospital reference range $22.4-34.5 \mathrm{~s}$ ). The next sample was obtained $3.75 \mathrm{~h}$ after initiation of the infusion, at which time the PTT was $34.6 \mathrm{~s}$. The UFH dosage was increased to 2500 units $/ \mathrm{h}$ ( 6 units/kg per hour). PTT measured $6.5 \mathrm{~h}$ later was $37.4 \mathrm{~s}$. With incremental dosage increases, it took about $25 \mathrm{~h}$ to reach therapeutic PTT (Table 1), where therapeutic PTT in the context of anticoagulant therapy is 1.5-2.5 times longer than the person's pretreatment level. Therapeutic PTT was maintained with a heparin dosage of 3500-4000 units/h (8.4-9.6 units/kg per hour). This compares well with the case presented by Myzienski and others ${ }^{3}$ (BMI $134 \mathrm{~kg} / \mathrm{m}^{2}$ ), in which therapeutic activated PTT was maintained with a dosage of 9.1-9.6 units/ $/ \mathrm{kg}$ per hour (based on absolute body weight). In the current case, heparin therapy was discontinued 3 days after initiation because of an interstitial IV line. Attempts to restart the IV administration of UFH were unsuccessful.

Twenty-four hours before the UFH infusion was stopped, warfarin therapy was initiated. Limited information about dosing of warfarin for obese individuals suggested that higher-than-usual doses would likely be needed. ${ }^{8}$ The study by Absher and others ${ }^{8}$ suggested that, in addition to obesity, factors such as male sex, age less than 55 years, African ethnicity, and vitamin K intake above $400 \mu \mathrm{g} / \mathrm{day}$ were independently predictive of warfarin requirements above $5 \mathrm{mg} /$ day. On the basis of this information and the patient's demographic 
Table 1. Timeline of PTT Testing and Heparin Dosing

\begin{tabular}{|c|c|c|c|c|c|}
\hline \multirow[b]{2}{*}{ Day of Admission } & \multicolumn{2}{|c|}{ PTT } & \multicolumn{3}{|c|}{ Heparin Infusion } \\
\hline & Sampling Time & PTT Value* (s) & $\begin{array}{l}\text { Time of Day } \\
\text { Order Written }\end{array}$ & $\begin{array}{l}\text { Rate of Infusion } \\
\text { (units/h) }\end{array}$ & $\begin{array}{c}\text { Rate of Infusion } \\
\text { (units/kg per hour) } \dagger\end{array}$ \\
\hline \multirow[t]{2}{*}{ Day 1 (baseline) } & 1705 & 27.7 & 1715 & 2000 & 4.8 \\
\hline & 2100 & 34.6 & 2130 & 2500 & 6.0 \\
\hline \multirow[t]{4}{*}{ Day 2} & 0355 & 37.4 & 0500 & 3000 & 7.2 \\
\hline & 1115 & 38.5 & 1300 & 3750 & 9.0 \\
\hline & 1800 & 53.3 & & No change in dosage & \\
\hline & 2315 & 65.9 & 2355 & 3500 & 8.4 \\
\hline \multirow[t]{3}{*}{ Day 3} & 0615 & 65.6 & 0900 & 3500 & 8.4 \\
\hline & 1200 & 53.4 & 1300 & 3750 & 9.0 \\
\hline & 1945 & 54.5 & 2040 & 4000 & 9.6 \\
\hline \multirow[t]{3}{*}{ Day 4} & 0305 & 71.6 & & No change in dosag & \\
\hline & 0725 & 76.6 & 1005 & 3750 & 9.0 \\
\hline & - & - & 1620 & IV interstitial & NA \\
\hline
\end{tabular}

$\mathrm{NA}=$ not applicable, $\mathrm{PTT}=$ partial thromboplastin time

*Hospital reference range for PTT: 22.4-34.5 s.

+Using absolute body weight.

\section{Table 2. Timeline of Warfarin Dosing while in Hospital}

\begin{tabular}{|c|c|c|c|c|}
\hline \multirow[b]{2}{*}{ Day of Admission* } & \multicolumn{2}{|c|}{ INRT } & \multicolumn{2}{|c|}{ Warfarin Administration } \\
\hline & Sampling Time & INR Value & Time of Day & Amount (mg) \\
\hline 1 (baseline) & 0305 & 1.2 & 1700 & 10 \\
\hline 2 & 0851 & 1.2 & 1700 & 7.5 \\
\hline 3 & 0845 & 1.2 & 1700 & 7.5 \\
\hline 4 & 0900 & 1.1 & 1700 & 12.5 \\
\hline 5 & 0756 & 1.2 & 1700 & 12.5 \\
\hline 6 & 1012 & 1.1 & 1700 & 25 \\
\hline 7 & 0955 & 1.5 & 1700 & 25 \\
\hline 8 & 1055 & 2.2 & 1700 & 20 \\
\hline 9 & 0720 & 2.7 & 1700 & 20 \\
\hline 10 & 0852 & 3.0 & 1700 & 15 \\
\hline 11 & 0701 & 3.0 & 1700 & 15 \\
\hline 12 & 0715 & 4.8 & 1700 & 12.5 \\
\hline 13 & 0725 & 3.1 & 1700 & 12.5 \\
\hline 14 & 0800 & 2.9 & 1700 & 12.5 \\
\hline 15 & 0720 & 3.0 & 1700 & 12.5 \\
\hline 16 & - & - & 1700 & 12.5 \\
\hline 17 & 0630 & 3.0 & 1700 & 12.5 \\
\hline 18 & - & - & 1700 & 12.5 \\
\hline 19 & - & - & 1700 & 12.5 \\
\hline 20 & 0758 & 2.6 & 1700 & 12.5 \\
\hline 21 & - & - & 1700 & 12.5 \\
\hline
\end{tabular}

characteristics (38-year-old white man), warfarin titration was started with $10 \mathrm{mg}$ on day 1 , followed by $7.5 \mathrm{mg}$ on days 2 and 3 (Table 2).

On day 5 , the patient was transferred to the provincial teaching hospital. Because the INR had not changed substantially since initial presentation, the warfarin dose was increased to $25 \mathrm{mg}$ (on days 6 and 7), and the first therapeutic INR (target 2-3) occurred on day 8. The patient's condition was eventually stabilized with a warfarin dose of $12.5 \mathrm{mg}$ daily. Three days after discharge (day 27 after initial presentation), at warfarin $12.5 \mathrm{mg}$ daily, the INR was 2.9 .

During the patient's hospital stay, scheduled oral medications included ferrous fumarate $300 \mathrm{mg}$ daily, vitamin D $2000 \mathrm{IU}$ daily, and vitamin $B_{12} 1000 \mu \mathrm{g}$ daily. No additional medications used during the patient's hospital stay were noted to interfere with the disposition of warfarin or heparin.

In summary, caution must be exercised when a weight-based UFH nomogram is used for patients with obesity. In this case, a common weight-based UFH nomogram would have elevated the patient's PTT into the toxic range, with associated risk of bleeding. The dose of UFH used to achieve therapeutic PTT in this patient agreed well with the limited information available for anticoagulation of a super-obese individual. A higher titrating dose of warfarin was needed to achieve the initial therapeutic INR, but the daily maintenance dose was only slightly higher than the standard 2 to $10 \mathrm{mg} /$ day that is commonly reported in the literature. 


\section{References}

1. Diepstraten J, van Kralingen S, Snijder R, Hackeng CM, van Ramshorst B, Knibbe C. Treatment of pulmonary embolism in an extremely obese patient. Obes Surg. 2009;19(8):1186-9.

2. Riney JN, Hollands JM, Smith JR, Deal EN. Identifying optimal initial infusion rates for unfractionated heparin in morbidly obese patients. Ann Pharmacother. 2010;44(7-8):1141-51.

3. Myzienski AE, Lutz MF, Smythe MA. Unfractionated heparin dosing for venous thromboembolism in morbidly obese patients: case report and review of the literature. Pharmacotherapy. 2010;30(3):105e-112e.

4. Davidson BL, Büller HR, Decousus H, Gallus A, Gent M, Piovella F, et al.; Matisse Investigators. Effect of obesity on outcomes after fondaparinux, enoxaparin, or heparin treatment for acute venous thromboembolism in the Matisse trials. J Thromb Haemost. 2007;5(6):1191-4.

5. Obesity: preventing and managing the global epidemic. Report of a WHO consultation on obesity. Tech Rep Ser 894. Geneva (Switzerland): World Health Organization; 2000.
6. Poirier P, Alpert MA, Fleisher LA, Thompson PD, Sugerman HJ, Burke LE, et al. Cardiovascular evaluation and management of severely obese patients undergoing surgery: a science advisory from the American Heart Association. Circulation. 2009;120(1):86-95.

7. Oria H, Brolin R, Deitel M, Gleysteen J, Marceau P, Martin L, et al. Guidelines for reporting results in bariatric surgery. Obes Surg. 1997;7(6):521-2.

8. Absher RK, Moore EE, Parker MH. Patient-specific factors predictive of warfarin dosage requirements. Ann Pharmacother. 2002;36(10):1512-7.

Keith Sine, BSc(Pharm), ACPR, PharmD

ICU Pharmacist

Pharmacy Department

Valley Regional Hospital

Kentville, Nova Scotia

Competing interests: None declared. 